\title{
Magnitude and associated factors of repeat induced abortion among reproductive age group women who seeks abortion Care Services at Marie Stopes International Ethiopia Clinics in Addis Ababa, Ethiopia
}

\author{
Bethelihem Alemayehu', Adamu Addissie ${ }^{2}$, Wondimu Ayele ${ }^{2}$, Sisay Tiroro ${ }^{3}$ and Demelash Woldeyohannes ${ }^{*^{*}}$ (i)
}

\begin{abstract}
Background: Repeated induced abortion is important public health concern both in the developing and developed world that increases maternal morbidity and mortality. The aim of this study was to determine the magnitude and associated factors of repeated induced abortion among abortion care service seekers at Marie Stopes International Ethiopia clinics in Addis Ababa, Ethiopia.

Methods: A cross sectional study was conducted among 429 women seeking abortion care at Marie Stopes International Ethiopia clinics. Simple random sampling technique was used to select study participants. Data were collected by trained data collectors using pretested structured questionnaires. Data were checked for completeness, consistency, coded and entered and analyzed through SPSS version 20. Bivariate and multivariate logistic regression analysis was computed to test the strength of association and the $p$-value $<0.05$ was considered as statistical significant.

Result: The magnitude of repeat induced abortion was 33.6\%. Based on this study age groups 20-24 years ( $\mathrm{AOR}=1.2 ; \mathrm{Cl}$ : 1.1-2.3), 25-29 years ( $A O R=5.4 ; C l: 3.1-6.2)$ and 30-34 years $(A O R=1.1 ; C l: 1.02-2.6)$; respondents with the educational level of primary $(A O R=0.2 ; C l: 0.070 .6)$, secondary $(A O R=0.4 ; C l: 0.2-0.8)$ and college diploma and above (AOR =0.4; $\mathrm{Cl}$ : 0.2-0.6); those with the monthly income of 1001-2000 Ethiopian birr (AOR $=4.2$; Cl: 1.8-9.4) and 2001-3000 Ethiopian birr $(A O R=0.3 ; C l: 0.2-0.9)$; those with years in marriage with $1-2$ years $(A O R=2.4 ; C l: 1.2-4.9)$ and those with last time of abortions of $1-2$ years, $2-3$ years and above 3 years, $(A O R=0.2 ; \mathrm{Cl}: 0.1-0.5),(A O R=0.1 ; \mathrm{Cl}: 0.05-0.4),(\mathrm{AOR}=0.4 ; \mathrm{Cl}: 0.2-$ 0.9 ), respectively were found to be significantly associated with repeat induced abortions.

Conclusion and recommendation: The magnitude of repeat induced abortion is similar with the reports from developing countries but it was lower than that of developed countries. Age group (20-24, 25-29 and 30-34 were positively associated with repeat induced abortion), educational level (primary, secondary and collage diploma and above were negatively associated with repeat induced abortion), monthly income (earn 1001-2000 Ethiopian birr were positively where as monthly income between 2001 and 3000 Ethiopian birr negatively associated), years in marriage (1-2 years was negatively associated) and time of last abortion (1-2 years, 2-3 years and above the three years were negatively associated) were the associated factors for repeat induced abortion. Health promotion messages are needed to focus to improve the knowledge of women about contraceptives as a primary prevention of repeated induced abortion.
\end{abstract}

Keywords: Repeat induced abortion, Reproductive age group, Ethiopia

\footnotetext{
* Correspondence: woldemel@gmail.com

${ }^{4}$ Department of Public Health, Collage of Medicine and Health Science,

Madda Walabu University, Bale Goba, Ethiopia

Full list of author information is available at the end of the article
}

(c) The Author(s). 2019 Open Access This article is distributed under the terms of the Creative Commons Attribution 4.0 International License (http://creativecommons.org/licenses/by/4.0/), which permits unrestricted use, distribution, and reproduction in any medium, provided you give appropriate credit to the original author(s) and the source, provide a link to the Creative Commons license, and indicate if changes were made. The Creative Commons Public Domain Dedication waiver (http://creativecommons.org/publicdomain/zero/1.0/) applies to the data made available in this article, unless otherwise stated. 


\section{Plain English summary}

Estimated 42 million induced abortions each year, nearly 20 million are performed in unsafe conditions and/or by unskilled providers and result in the deaths of an estimated 47,000 girls and women. This represents about $13 \%$ of all pregnancy-related deaths. Almost all unsafe abortions take place in developing countries, and this is where $98 \%$ of abortion-related deaths occur. This study aimed in showing the magnitude and associated factors of repeat induced abortion at facility based data. This will help for the policy makers and program implementers to consider the prevention of repeat induced abortion and its associated factors at facility and community based level. Facility based cross-sectional study design was conducted to assess the magnitude and associated factors of repeat induced abortion among the women who seeks abortion services at Marie Stopes International Ethiopia Clinics in Addis Ababa. From 442 95\% of the study participants were included in the study. The mean age of the study participants was 26 years. This study showed the magnitude of repeat induced abortion was $33.6 \%$. Whereas study participants age groups, respondents educational level, monthly income, years in marriage and the time for last abortions was the factors associated with induced abortion. In conclusion the magnitude of repeat induced abortion is similar with the reports from developing countries but it was lower than that of developed countries. Hence, health promotion messages are needed to focus to improve the knowledge of women about contraceptives as a primary prevention of repeated induced abortion.

\section{Introduction}

Abortion is a sensitive and contentious issue with religious, moral, cultural, and political dimensions. It is also a public health concern in many parts of the world. The World Health Organization (WHO) estimates that worldwide 210 million women become pregnant each year and that about two-thirds of them, or approximately 130 million, deliver live infants. The remaining one third of pregnancies ends in miscarriage, stillbirth, or induced abortion. Of the estimated 42 million induced abortions each year, nearly 20 million are performed in unsafe conditions and/or by unskilled providers and result in the deaths of an estimated 47,000 girls and women. This represents about $13 \%$ of all pregnancy-related deaths. Almost all unsafe abortions take place in developing countries, and this is where $98 \%$ of abortion-related deaths occur [1].

A studies shows unsafe abortions were responsible for nearly one-third of maternal deaths in Africa, and
WHO reports that in the countries of sub-Saharan Africa unsafe abortions are responsible for $50 \%$ of maternal deaths. Women in developed and developing regions of the world turn to abortion at similar rates; annually, 29 abortions are performed per 1000 women in developing countries, compared with 26 per 1000 women in developed countries [1, 2].

The ages at which women have repeat induced abortion differ markedly across regions. Nearly $60 \%$ of women in sub-Saharan Africa who have repeat induced abortion are younger than 25, and 25\% are still in their teens. In Asia, $70 \%$ of repeat induced abortions are among women 25 and older; many of them already have children and want to limit family size. In Latin America and the Caribbean, more than half of repeat induced abortions occur among women who are in their 20s, suggesting that women in this region use repeat induced abortion to space births and limit family size [3].

Furthermore, there is no standard definition of repeat induced abortion; some studies count more than one abortion ever, others focused on multiple abortions within shorter intervals [4, 5]. A Canadian study found more similarities than differences among firsttime and repeat abortion clients [6]. More recent research has identified an array of potential risk factors for repeat induced abortion including: age; socioeconomic status; parity; education; foreign origin; race; smoking; alcohol/drug abuse; physical abuse or violence; early sexual debut; previous contraceptive use; and type of contraceptives used [5].

Previous research mainly in high income countries has identified common risk factors for repeat abortions, including higher age, higher parity, and lower socioeconomic status. Evidence from the United States clearly showed that the women with repeat abortion were as highly as those with one -time abortion to use contraception [6-8].

In Russia one clinic based survey estimated that repeat abortion accounts for approximately 60\% of all abortions and another Russian community based study revealed that repeat abortions were associated with low education and alcohol use, and it is more common under 35 years of women $[9,10]$.

Facility based cross sectional study at Nepal indicated that the magnitude of repeat abortion among abortion service care seeker is 32.3\% (95\% CI 29.634.9) and this study determined that age and parity, and women with no intention of having a future child, with those attaining primary or secondary education level and those attending the nongovernmental sector clinics were the main associated factors for repeat abortion among the abortion care seekers [11]. 
A facility based cross sectional study in Sweden outlined that parity, lack of emotional support, being unemployed or on sick leave, daily tobacco use, and compulsory school or high school as the highest educational level were the associated factors for repeat abortion among women aged 20-49 years [12].

Different studies showed that various risk factors for repeat abortion, for instance, the risk of repeat abortion has been found to be related to several socioeconomic factors, such as immigrant status and weak social networks $[12,13]$, low educational level and unemployment $[14,15]$. A correlation between repeat abortion and a history of violence and sexual abuse has been found [16], and parity and smoking are more common among women with repeat abortions $[17,18]$.

Even some studies done some years back in Ethiopia, which shows the magnitude and associated factors for induced abortion at community and facility base, but still there is limitation of studies done on the magnitude and associated factors for repeat induced abortion. So, this study aimed in showing the magnitude and associated factors of repeat induced abortion at facility based data. This will help for the policy makers and program implementers to consider the prevention of repeat induced abortion and its associated factors at facility and community based level.

\section{Methodology}

\section{Study area and period}

The study was conducted at Marie Stopes International Ethiopia (MSIE) clinics in Addis Ababa, Ethiopia which is non-governmental profit based organization providing different kinds of services to the community, including FP services, ANC, PNC, deliver, abortion and post abortion care services in large. Before one month of starting this study a total of 1209 women received abortion services in all branches of MSIE clinics (i.e. Kirkose 399, Arada 360, Teklehaymenot 279 and Gulale 180) in Addis Ababa. This study was conducted from April 1 to April 30, 2015 at MSIE clinics in Addis Ababa, Ethiopia.

\section{Study design}

Facility based cross-sectional study design was conducted to assess the magnitude and associated factors of repeat induced abortion among the women who seeks abortion services at MSIE clinics in Addis Ababa, Ethiopia.

\section{Population}

\section{Source population}

The source populations for this study were all women who were (at the age of 15-49 years) taken abortion care services of the MSIE clinics in Addis Ababa, Ethiopia.

\section{Study population}

All women aged 15-49 who were seeking abortion care services during the study period.

\section{Inclusion and exclusion criteria Inclusion criteria}

All women aged 15-49 who were received abortion care services from MSIE clinics were included in the study.

\section{Exclusion criteria}

Women who were not volunteer to participate in the study, women who were critically ill and women who were not available during the data collection period were excluded from the study.

\section{Sample size determination}

The sample size of the study was determined using the single population proportion formula based on the assumption that the prevalence rate of repeat induced abortion was $50 \%$ (since there is no previous studies done on the area), and 95\% confidence interval was used with a marginal error of $5 \%$ and by taking the non-response rate as $15 \%$ due to sensitivity of the issue.

$$
\mathrm{n}=\frac{\left(\mathrm{Z}_{\alpha / 2}\right)^{2} \times \mathrm{P}(1-\mathrm{P})}{\mathrm{d}^{2}}
$$

Where: $\mathrm{n}=$ sample size.

$\mathrm{P}=$ proportion of repeat induced abortion.

$\mathrm{q}=1-\mathrm{p}$.

$\mathrm{d}=$ desired degree of precision (5\%).

$\mathrm{Z}=$ is the standard normal value at $95 \%$ confidence level, which is 1.96

$$
\begin{aligned}
\mathrm{n} & =\frac{(1.96)^{2} \times 0.5 \times 0.5}{(0.05)^{2}}=384.16 \\
& =15 \% \text { of non-response rate was assumed } \\
& \text { the total sample size was } 442
\end{aligned}
$$

\section{Sampling procedure}

For each Marie Stopes service provision unit the allocated sample size was calculated using the monthly total number of women of all the service provision units, the monthly visiting number women from each unit and the total sample size. Finally simple random sampling methods were employed to select the study participants from each service provision units of MSIE clinics. 


\section{Study variables}

\section{Dependent variable}

Repeat induced abortion.

\section{Independent variables}

Socio-demographic characteristics (age, marital status, educational status, economic status, residence), Years in marriage, Family history, Number of pregnancy, Time of last pregnancy, Number of previous abortion, Time of last abortion, and Methods used for last abortion.

\section{Operational definition}

Repeat induced abortion: - refers for the women who having more than one pregnancy termination, without any medical or surgical indication.

\section{Data collection tools and procedures}

The data collection instruments were structured questionnaires which consist of both open and closed ended questions. It was first prepared in English version and latter on translated to Amharic version, which is local language. The data collectors were eight diploma nurses who were working outside of MSIE clinics, and additional three BSc nurses were recruited for supervision. Full 3 days training was given for data collectors and supervisors on the methods of collecting data through interviewing the clients. How to fill the information on questionnaire, the ethical aspect in keeping the confidentiality of their information were another focus of the training. The supervisors had monitored the data collection process of the data collectors and taken corrective measures with consultation of principal investigator.

\section{Data quality control}

To ensure the quality of the data, the questionnaire was prepared using simple and easily understandable language and also translated in to local language (Amharic), and 3 days training was given for data collectors prior to data collection. Pre-test was done outside the study area on 5\% questionnaires and modifications were done accordingly. During data collection, the supervisors monitored the collection process by checking completeness of the data and took the correction on the spot of data collection site when any problem happened and the principal investigator rechecked the completeness of the data. Data were checked again for its completeness during data entry and the cleaning process was done by running simple frequency after data entry for its consistency. When inconsistency happens to the data, it was checked again by referring the hard questionnaire. Finally, data analysis was begun after completion of the cleaning process.

\section{Data processing and analysis}

Data was collected from the respondents; entry and analysis were done using SPSS, version 20. Descriptive statistics such as frequency, proportion, means and standard deviation (SD) were computed. To estimate the magnitude of the association between associated factors and repeat induced abortion, odds ratio (OR) with 95\% confidence intervals (CIs) was used. A logistic regression model was used for both bivariate and multivariate analysis in order to identify associated factors of repeat induced abortion among groups of independent variables. Variables which were significantly associated $(p$ $<0.05)$ with repeat induced abortion in the binary logistic regression analysis were entered in to the multivariate logistic regression analysis model. The findings were expressed in AOR with 95\% CIs and significant threshold was declared at $p<0.05$.

\section{Ethical consideration}

This study was done after getting ethical clearance from Research and ethical committee of the school of public health, Addis Ababa University. Written permission was also secured from MSIE clinics and verbal consent was obtained from the participants during the data collection.

\section{Result \\ Socio-demographic characteristics of the study participants}

A total of 429 participants with a mean age of 26 years were included in this study with a response rate was $97 \%$ (i.e. 30 study participants were not voluntary to participate on this study), of these $41 \%$ of them were at the age interval of 25-29 years. $91 \%$ of the study participants were from urban areas. Regarding to marital status $55 \%$ of them married and $37.5 \%$ were never married (Table 1).

\section{Past and current reproductive history of the study participants}

Of the total respondents, 268 of them had past and current reproductive histories and $41 \%$ had married at the age of 15-19 years and $29 \%$ of them were in marriage for less than 1 year. Medications were used by $66 \%$ of the respondents to induce abortion (Table 2).

\section{Factors associated with repeat induced abortion at MSIE clinics}

Socio-demographic characteristics associated with repeat induced abortion

On bivariate analysis age of the study participants, educational status and monthly income were significantly associated with the outcome variable, but residence, 
Table 1 The socio-demographic characteristics of the women who seek abortion care services at MSIE clinics in Addis Ababa, Ethiopia, from April 1 to April 30, 2015

\begin{tabular}{|c|c|c|}
\hline Variables & Number $(n=429)$ & Percent \\
\hline \multicolumn{3}{|l|}{ Age } \\
\hline $15-19$ & 20 & 4.7 \\
\hline $20-24$ & 133 & 31.0 \\
\hline $25-29$ & 176 & 41.0 \\
\hline $30-34$ & 88 & 20.5 \\
\hline $35-39$ & 12 & 2.8 \\
\hline \multicolumn{3}{|l|}{ Residence } \\
\hline Urban & 393 & 91.6 \\
\hline Rural & 36 & 8.4 \\
\hline \multicolumn{3}{|l|}{ Educational status } \\
\hline Illiterate & 36 & 8.4 \\
\hline Elementary & 92 & 21.4 \\
\hline Secondary & 138 & 32.2 \\
\hline College diploma \& above & 163 & 38.0 \\
\hline \multicolumn{3}{|l|}{ Religion } \\
\hline Orthodox & 330 & 76.9 \\
\hline Muslim & 71 & 16.6 \\
\hline Protestant & 24 & 5.6 \\
\hline Others & 4 & 0.9 \\
\hline \multicolumn{3}{|l|}{ Ethnicity } \\
\hline Amhara & 213 & 49.7 \\
\hline Oromo & 88 & 20.5 \\
\hline Tigre & 46 & 10.7 \\
\hline Gurage & 66 & 15.4 \\
\hline Others & 16 & 3.7 \\
\hline \multicolumn{3}{|l|}{ Marital status } \\
\hline Married & 236 & 55.0 \\
\hline Never married & 161 & 37.5 \\
\hline Divorced & 28 & 6.5 \\
\hline Widowed & 4 & 0.9 \\
\hline \multicolumn{3}{|l|}{ Occupational status } \\
\hline House wife & 83 & 19.3 \\
\hline Student & 39 & 9.1 \\
\hline Government employee & 46 & 10.7 \\
\hline Private employee & 233 & 52.0 \\
\hline House made & 24 & 5.6 \\
\hline Others & 14 & 3.3 \\
\hline \multicolumn{3}{|l|}{ Monthly income (ETB) } \\
\hline$<500$ & 149 & 34.7 \\
\hline $501-1000$ & 67 & 15.6 \\
\hline $1001-2000$ & 59 & 13.8 \\
\hline $2001-3000$ & 44 & 10.3 \\
\hline > 3001 & 110 & 25.6 \\
\hline
\end{tabular}

ETB Ethiopian Birr, $<=$ less than, $>=$ more than marital status and occupation were not associated with the outcome variable. Study participants who were at the educational level of diploma and above were 3 times $(\mathrm{COR}=3.0, \mathrm{CI} ; 1.3-7.1)$ more likely to have repeat induced abortion than illiterates (Table 3).

\section{Past and current reproductive histories associated with repeat induced abortion at MSIE clinics}

On bivariate analysis years in marriage and time of last pregnancy were significantly associated with repeat induced abortion, but family size, time of last pregnancy, planned pregnancy, reason of the abortion and methods used for the abortion were not associated with repeat induced abortion. Women who were $5-10$ years in marriage were 2 times $(\mathrm{COR}=2.3, \mathrm{CI}$; 1.3-4.2) more likely to have repeat induced abortion than those who were less than 1 year (Table 4).

\section{Multivariate analysis for factors associated with repeat induced abortion at MSIE clinics}

After controlling for potential confounder on multiple logistic regression analysis age, educational status, monthly income, years in marriage, time of last abortion were significantly associated with repeat induced abortion among abortion care seekers at MSIE clinics in Addis Ababa, Ethiopia. Respondents who were at the age of $25-29$ years were $5.4(\mathrm{AOR}=5.4,95 \% \mathrm{CI}$; 3.1-6.2) times more likely to had repeat induced abortion than those who were at the age of 15-19 years. Study participants who were illiterates were $60 \%$ less risky than those who have secondary and college diploma educational levels (Table 5).

\section{Discussion}

Repeat induced abortion, or having more than one pregnancy termination, is bound in a vicious cycle with repeat unintended pregnancy. Women who have had a recent abortion are more likely to discontinue contraceptive use during a 1-year follow up period and both recent and other previous abortion clients have been found to be more likely to have a (repeat) unintended pregnancy during that time period [19].

This study revealed that the magnitude of repeat induced abortion among abortion care service seekers at Marie Stopes International Ethiopia clinics was $33.6 \%$. This is similar with study done in Ethiopia with the magnitude of $30 \%$. It is consistent with the facility based cross sectional study from Nepal with the magnitude of repeat induced abortion of $32.5 \%$ among the reproductive age group of women who seeks abortion care $[14,19,20]$.

Also it is similar with study done both in developed and developing countries. For instance, this finding is 
Table 2 Past and current reproductive history of the women who seek abortion care services at MSIE clinics in Addis Ababa, Ethiopia, from April 1 to April 30, 2015

Frequency

\begin{tabular}{l} 
Variable \\
\hline Age at marriage \\
$15-19$ \\
$20-24$ \\
$25-29$ \\
$30-34$ \\
Total \\
Years in marriage \\
$\leq 1$ year \\
$1-2$ years \\
$2-5$ years \\
$5-10$ years \\
$\geq 10$ years \\
Total \\
Family size \\
$1-2$ \\
$3-4$ \\
$5-6$ \\
$\geq 7$ \\
Total
\end{tabular}

Number of pregnancy

1

2

3

4

5

$\geq 6$

Total

Time of last pregnancy

$$
\begin{aligned}
& <1 \text { year } \\
& 1-2 \text { years } \\
& 2-3 \text { years } \\
& \geq 3 \text { years } \\
& \text { Total }
\end{aligned}
$$

Was the last pregnancy wanted

$$
\text { Yes }
$$

No

Total

Age of the last pregnancy

$$
\begin{aligned}
& <1 \text { year } \\
& 1-2 \text { years } \\
& 2-3 \text { years } \\
& \geq 3 \text { years }
\end{aligned}
$$

112

52

268

128

59

73
61.8

29.6

5.4

3.3

100.0

27.7

72.3

100.0

24.2

23.8

13.9

38.1
Percent

Table 2 Past and current reproductive history of the women who seek abortion care services at MSIE clinics in Addis Ababa, Ethiopia, from April 1 to April 30, 2015 (Continued)

\begin{tabular}{lll}
\hline Variable & Frequency & Percent \\
\hline Total & 244 & 100.0 \\
Number of previous abortion & & \\
1 time & 285 & 66.4 \\
$>=2$ times & 144 & 33.6 \\
Total & 429 & 100.0 \\
Reason of abortion & & \\
Being single & 135 & 35 \\
Schooling & 75 & 17.5 \\
To space & 16 & 3.7 \\
Economic problem & 144 & 33.6 \\
Separation & 39 & 9.1 \\
Others & 20 & 4.7 \\
Total & 429 & 100.0 \\
Time of last abortion & & \\
Below 1 year & 245 & 57.1 \\
1-2 years & 92 & 21.4 \\
2-3 years & 41 & 9.6 \\
Above 3 years & 51 & 11.9 \\
Total & 429 & 100.0
\end{tabular}

Abortion was performed by

Trained person
Untrained person
Self-abortion

Methods used for abortion

$\begin{array}{lll}\text { Medications } & 283 & 66.0 \\ \text { MVA } & 146 & 34.0 \\ \text { Total } & 429 & 100.0\end{array}$

Note: MVA Manual Vacuum Aspiration

similar with facility based cross sectional study's results of Canada (35.5\%) [21], Finland (32\%) [22], New Zealand (36\%) [23] and Sweden (37\%) [24]. Also this result is comparable with the findings from developing countries such as facility based study from Kenya (16\%) [25], Sudan (40\%) [26]. This is may be because of the women in developed and developing regions of the world turn to abortion at similar rates; annually, 29 abortions are performed per 1000 women in developing countries, compared with 26 per 1000 women in developed countries.

Several studies have identified different factors which affect the rate of repeat induced abortion among the reproductive age group of women in both developed and developing countries.

Russian clinic based cross sectional study revealed that low educational status and age below 35 years were the associated factors of repeat induced abortions [10], the 
Table 3 Socio-demographic characteristics associated with repeat induced abortion among the women who seek abortion care services at MSIE clinics in Addis Ababa, Ethiopia, from April 1 to April 30, 2015

\begin{tabular}{|c|c|c|c|c|}
\hline \multirow[t]{2}{*}{ Variables } & \multicolumn{2}{|c|}{ Induced abortion } & \multirow[t]{2}{*}{ COR,95\% Cl } & \multirow[t]{2}{*}{$P$-value } \\
\hline & $\begin{array}{l}\text { Aborted once } \\
N(\%)\end{array}$ & $\begin{array}{l}\text { Repeat abortion } \\
N(\%)\end{array}$ & & \\
\hline \multicolumn{5}{|l|}{ Age } \\
\hline $15-19$ & $20(7.0)$ & $0(0.0)$ & 0.00 & 0.998 \\
\hline $20-24$ & $89(31.2)$ & $44(30.6)$ & $0.2(.07-0.8)$ & 0.029 \\
\hline $25-29$ & $120(42.1)$ & $56(38.9)$ & $0.2(0.06-0.8)$ & 0.022 \\
\hline $30-34$ & $52(18.2)$ & $36(25.0)$ & $0.3(0.09-1.2)$ & 0.102 \\
\hline $35-39$ & $4(1.4)$ & $8(5.6)$ & 1.0 & \\
\hline \multicolumn{5}{|l|}{ Residence } \\
\hline Urban & $261(91.6)$ & $132(91.7)$ & $1.0(0.5-2.0)$ & 0.975 \\
\hline Rural & $24(8.4)$ & $12(8.3)$ & 1.0 & \\
\hline \multicolumn{5}{|l|}{ Educational status } \\
\hline Illiterate & $28(9.8)$ & $8(5.6)$ & 1.0 & \\
\hline Elementary & $64(22.5)$ & $28(19.4)$ & $1.5(0.6-3.7)$ & 0.355 \\
\hline Secondary & $106(37.2)$ & $32(22.2)$ & $1.1(0.4-2.5)$ & 0.902 \\
\hline College diploma \& above & $87(30.5)$ & $76(52.8)$ & $3.1(1.3-7.1)$ & 0.009 \\
\hline \multicolumn{5}{|l|}{ Marital status } \\
\hline Married & $152(53.3)$ & $84(58.3)$ & 1.0 & \\
\hline Single & $113(39.6)$ & $48(33.3)$ & $0.7(0.5-1.2)$ & 0.231 \\
\hline Divorced & $16(5.6)$ & $12(8.3)$ & $1.3(0.6-3.0)$ & 0.451 \\
\hline Widowed & $4(1.4)$ & $4(0.9)$ & 0.000 & 0.999 \\
\hline \multicolumn{5}{|l|}{ Occupation } \\
\hline House wife & $55(19.3)$ & $28(19.4)$ & 1.0 & \\
\hline Student & $27(9.5)$ & $12(8.3)$ & $0.8(.3-1.9)$ & 0.745 \\
\hline Government employee & 34 (11.9) & $12(8.3)$ & $0.7(0.3-1.5)$ & 0.370 \\
\hline Private employee & $143(50.2)$ & $80(55.6)$ & $1.1(0.6-1.8)$ & 0.728 \\
\hline House made & $20(7.0)$ & $4(2.8)$ & $0.4(0.1-1.2)$ & 0.116 \\
\hline Others & $6(2.1)$ & $8(5.6)$ & $2.6(0.8-8.2)$ & 0.101 \\
\hline \multicolumn{5}{|l|}{ Monthly income } \\
\hline$<500$ & $97(34.0)$ & $52(36.1)$ & $1.1(0.6-1.8)$ & 0.715 \\
\hline $501-1000$ & 55 (19.3) & $12(8.3)$ & $0.4(0.2-0.9)$ & 0.034 \\
\hline $1001-2000$ & $27(9.5)$ & $32(11.2)$ & $2.4(1.2-4.4)$ & 0.007 \\
\hline $2001-3000$ & $32(11.2)$ & $12(8.3)$ & $0.7(0.3-1.6)$ & 0.510 \\
\hline$\geq 3000$ & $74(26.0)$ & $36(25.0)$ & 1.0 & \\
\hline
\end{tabular}

present study supports this study findings, here in this study all the participants under the age of 35 years were statistically significantly associated for the repeat induced abortion with different values of (adjusted) odds ratio and $p$-values.

This study showed that age under 35 years, low educational status and middle economic status were the main associated factors of repeat induced abortion among the abortion care seekers, and this finding is supported by the study from Nepal for the factor age and low educational status [14].

A study from Kenya showed that being separated or divorced or widowed and using traditional contraception methods were associated with a higher likelihood of a repeat abortion [25], however, in this study the majority of the participants who had repeat induced abortions were married (58.3\%) and single (33.3\%) but they are not statistically significant. 
Table 4 Past and current reproductive histories associated with repeat induced abortion among the women who seeks abortion care services at MSIE clinics in Addis Ababa, Ethiopia, from April 1 to April 30, 2015

\begin{tabular}{|c|c|c|c|c|}
\hline \multirow[t]{2}{*}{ Variables } & \multicolumn{2}{|l|}{ Induced abortion } & \multirow[t]{2}{*}{ COR,95\%Cl } & \multirow[t]{2}{*}{$P$-value } \\
\hline & Aborted once $N(\%)$ & Repeat abortion $N(\%)$ & & \\
\hline \multicolumn{5}{|l|}{ Years in marriage } \\
\hline Less than 1 year & $92(32.3)$ & $36(25.0)$ & 1.0 & \\
\hline $1-2$ years & $48(16.8)$ & $11(7.6)$ & $0.5(0.2-1.2)$ & 0.168 \\
\hline $2-5$ years & $42(14.7)$ & $31(21.5)$ & $1.8(1.0-3.4)$ & 0.039 \\
\hline $5-10$ years & $42(14.7)$ & $39(27.1)$ & $2.3(1.3-4.2)$ & 0.004 \\
\hline Above 10 years & $61(21.4)$ & $27(18.8)$ & $1.1(0.6-2.0)$ & 0.685 \\
\hline Total & $66.4 \%$ & $33.6 \%$ & & \\
\hline \multicolumn{5}{|l|}{ Family size } \\
\hline $1-2$ & $88(30.9)$ & $52(36.1)$ & $0.9(0.4-2.1)$ & 0.970 \\
\hline $3-4$ & $116(40.7)$ & $36(25.0)$ & $0.5(0.2-1.1)$ & 0.110 \\
\hline $5-6$ & $61(21.4)$ & $44(30.6)$ & $1.2(0.5-2.7)$ & 0.657 \\
\hline Above 7 & $20(7.0)$ & $12(8.3)$ & 1.0 & \\
\hline \multicolumn{5}{|c|}{ Time last of pregnancy } \\
\hline$<1$ year & $161(56.5)$ & $104(72.2)$ & $1.6(0.5-5.2)$ & 0.428 \\
\hline $1-2$ years & $97(34.0)$ & $30(20.8)$ & $0.7(0.2-2.6)$ & 0.682 \\
\hline $2-3$ years & $17(6.0)$ & $6(4.2)$ & $0.8(0.2-3.9)$ & 0.869 \\
\hline Above 3 years & $10(3.5)$ & $4(2.8)$ & 1.0 & \\
\hline \multicolumn{5}{|c|}{ Was the pregnancy planed } \\
\hline Yes & 79 (27.7) & $40(27.8)$ & 1.0 & \\
\hline No & $206(72.3)$ & $104(72.2)$ & $0.9(0.6-1.5)$ & 0.990 \\
\hline \multicolumn{5}{|c|}{ Reason of the abortion } \\
\hline Being single & $84(29.5)$ & $51(35.4)$ & $2.4(0.7-7.6)$ & 0.130 \\
\hline Schooling & $50(17.5)$ & $25(17.4)$ & $2.0(0.6-6.6)$ & 0.256 \\
\hline Spacing & $12(4.2)$ & $4(2.8)$ & $1.3(0.2-6.4)$ & 0.720 \\
\hline Economic problem & $100(35.1)$ & $44(30.6)$ & $1.7(0.5-5.50$ & 0.336 \\
\hline Separation & $23(8.1)$ & $16(11.10$ & $2.7(0.7-9.8)$ & 0.114 \\
\hline Others & $16(5.6)$ & $4(2.8)$ & 1.0 & \\
\hline \multicolumn{5}{|l|}{ Time of last abortion } \\
\hline 1 month-1 year & $149(52.3)$ & $96(66.7)$ & 1.0 & \\
\hline $1-2$ years & $69(24.2)$ & $23(16.0)$ & $0.5(0.3-0.8)$ & 0.016 \\
\hline $2-3$ years & $32(11.2)$ & $9(6.2)$ & $0.4(0.2-0.9)$ & 0.038 \\
\hline Above 3 years & 35 (12.3) & $16(11.1)$ & $0.7(0.3-1.3)$ & 0.297 \\
\hline \multicolumn{5}{|c|}{ Methods used for abortion } \\
\hline Medication & $183(64.2)$ & $100(69.4)$ & 1.0 & \\
\hline MVA & $102(35.8)$ & $44(30.6)$ & $0.7(0.5-1.2)$ & 0.280 \\
\hline
\end{tabular}

Note: MVA Manual Vacuum Aspiration

This may be because of the fact that, at present study the participants were only taken from the Marie Stopes International Ethiopia clinics which is a profit based nongovernmental organization, so this limitation of the sample may not be representative of the whole population as like that of Kenya which was done in five public different hospitals with large sample size.

\section{Conclusion and recommendation} Conclusion

The magnitude of repeat induced abortion is similar with the reports from developing countries but it was lower than that of developed countries. Age group (20$24,25-29$ and 30-34 were positively associated with repeat induced abortion), educational level (primary, 
Table 5 Multivariate analysis for factors associated with repeat induced abortion among women who seeks abortion care services at MSIE clinics in Addis Ababa, Ethiopia, from April 1 to April 30, 2015

\begin{tabular}{|c|c|c|c|c|c|}
\hline \multirow[t]{2}{*}{ Variables } & \multicolumn{2}{|c|}{ Induced abortion } & \multirow[t]{2}{*}{$\mathrm{COR}, 95 \% \mathrm{Cl}$} & \multirow[t]{2}{*}{$\mathrm{AOR}, 95 \% \mathrm{Cl}$} & \multirow[t]{2}{*}{$P$-value } \\
\hline & Aborted Once & Repeat Abortion & & & \\
\hline \multicolumn{6}{|l|}{ Age } \\
\hline $15-19$ & $20(7.0)$ & $0(0.0)$ & 0.00 & 0.00 & 0.00 \\
\hline $20-24$ & $89(31.2)$ & $44(30.6)$ & $0.2(.07-0.8)$ & $1.2(1.1-2.3)$ & 0.001 \\
\hline $25-29$ & $120(42.1)$ & $56(38.9)$ & $0.2(0.06-0.8)$ & $5.4(3.1-6.2)$ & 0.001 \\
\hline $30-34$ & $52(18.2)$ & $36(25.0)$ & $0.3(0.09-1.2)$ & $1.1(1.02-2.6)$ & 0.009 \\
\hline $35-39$ & $4(1.4)$ & $8(5.6)$ & 1.0 & 1.0 & \\
\hline \multicolumn{6}{|l|}{ Educational status } \\
\hline Illiterate & $28(9.8)$ & $8(5.6)$ & 1.0 & 1.0 & \\
\hline Elementary & $64(22.5)$ & $28(19.4)$ & $1.5(0.6-3.7)$ & $0.2(0.07-0.6)$ & 0.006 \\
\hline Secondary & $106(37.2)$ & $32(22.2)$ & $1.1(0.4-2.5)$ & $0.4(0.2-0.8)$ & 0.011 \\
\hline College diploma \& above & $87(30.5)$ & $76(52.8)$ & $3.1(1.3-7.1)$ & $0.4(0.2-0.6)$ & 0.001 \\
\hline \multicolumn{6}{|l|}{ Monthly income } \\
\hline$<500$ & $97(34.0)$ & $52(36.1)$ & $1.1(0.6-1.8)$ & $1.5(0.8-2.9)$ & 0.205 \\
\hline $501-1000$ & $55(19.3)$ & $12(8.3)$ & $0.4(0.2-0.9)$ & $0.9(0.36-2.2)$ & 0.819 \\
\hline $1001-2000$ & $27(9.5)$ & $32(11.2)$ & $2.4(1.2-4.4)$ & $4.2(1.8-9.4)$ & $<0.001$ \\
\hline $2001-3000$ & $32(11.2)$ & $12(8.3)$ & $0.7(0.3-1.6)$ & $0.3(0.2-0.9)$ & 0.039 \\
\hline$\geq 3000$ & $74(26.0)$ & $36(25.0)$ & 1.0 & 1.0 & \\
\hline \multicolumn{6}{|l|}{ Years in marriage } \\
\hline Less than 1 year & $92(32.3)$ & $36(25.0)$ & 1.0 & 1.0 & \\
\hline $1-2$ years & $48(16.8)$ & $11(7.6)$ & $0.5(0.2-1.2)$ & $2.4(1.2-4.9)$ & 0.047 \\
\hline $2-5$ years & $42(14.7)$ & $31(21.5)$ & $1.8(1.0-3.4)$ & $1.8(0.8-3.9)$ & 0.139 \\
\hline $5-10$ years & $42(14.7)$ & $39(27.1)$ & $2.3(1.3-4.2)$ & $1.1(0.5-2.8)$ & 0.689 \\
\hline Above 10 years & $61(21.4)$ & $27(18.8)$ & $1.1(0.6-2.0)$ & $0.7(0.3-1.8)$ & 0.56 \\
\hline \multicolumn{6}{|l|}{ Time of last abortion } \\
\hline 1 month-1 year & $149(52.3)$ & $96(66.7)$ & 1.0 & 1.0 & \\
\hline $1-2$ years & $69(24.2)$ & $23(16.0)$ & $0.5(0.3-0.8)$ & $0.2(0.1-0.5)$ & $<0.001$ \\
\hline $2-3$ years & $32(11.2)$ & $9(6.2)$ & $0.4(0.2-0.9)$ & $0.1(0.05-0.4)$ & $<0.001$ \\
\hline Above 3 years & $35(12.3)$ & $16(11.1)$ & $0.7(0.3-1.3)$ & $0.4(0.2-0.9)$ & 0.039 \\
\hline
\end{tabular}

secondary and collage diploma and above were negatively associated with repeat induced abortion), monthly income (earn 1001-2000 Ethiopian birr were positively where as monthly income between 2001 and 3000 Ethiopian birr negatively associated), years in marriage (1-2 years was negatively associated) and time of last abortion (1-2 years, $2-3$ years and above the 3 years were negatively associated) were the associated factors for repeat induced abortion. Health promotion messages are needed to focus to improve the knowledge of women about contraceptives as a primary prevention of repeated induced abortion. .

\section{Recommendation}

Based on the finding of this study the following important recommendations are forwarded for the respective bodies' such as clinicians, patients, health educators, policy makers, program implementers and researchers who will engage on sexual and reproductive areas as of one main public health concern.

\section{For organizations and institutions}

The ministry of health should have undertake the survey studies either at facility based or community based level to determine the prevalence of repeat induced abortion and its associated factors, Since we did not have the identified prevalence of repeat abortion at national level .

\section{For health workers}

Health promotion messages are needed to focus to improve the knowledge of women about contraceptives as a primary prevention of repeat induced abortion. 


\section{Patients}

Awareness creation on the patients on the impact of induced abortion and repeat induced abortion for their future health and IEC for the clients' towards family planning during post abortion care time.

\section{For researchers}

Finally, it is better to conduct further large scale epidemiological research with large sample size at population level (using both qualitative and quantitative methods).

\section{Abbreviations}

ANC: Antenatal Care; AOR: Adjusted Odd Ratio; BSc: Bachelor of Science; Cl: Confidence Interval; FP: Family planning; IEC: Information Education Communication; MSIE: Marie Stopes International Ethiopia; PNC: Postnatal Care

\section{Acknowledgments}

We thank all study participants for devoting their precious time to take part in this study.

\section{Ethics approval and consents to participation}

This study was done after getting ethical clearance from Research and ethical committee of the school of public health, Addis Ababa University. Written permission was also secured from MSIE clinics and verbal consent was obtained from the participants during the data collection.

\section{Authors' contributions}

All authors carried out conception, design, analysis, interpretation, report, and manuscript writing. And all authors read and approved the final manuscript.

\section{Funding}

Not applicable.

\section{Availability of data and materials}

The datasets generated and/or analyzed during the current study are not publicly available due to confidentiality. If anyone wants to have a data may contact the corresponding author for data access using the following address: Email:woldemel@gmail.com, P. O.B. 554 and Phone number + 251912097351

\section{Consent for publication}

Not applicable.

\section{Competing interests}

The authors declare that they have no competing interests.

\section{Author details}

${ }^{1}$ Marie Stopes International Ethiopia Clinic, Addis Ababa, Ethiopia. ${ }^{2}$ School of Public Health, College of Health Sciences, Department of Preventive Medicine, Addis Ababa University, Addis Ababa, Ethiopia. ${ }^{3}$ National Defense Health Main Department, Health promotion and Disease prevention department, Addis Ababa, Ethiopia. ${ }^{4}$ Department of Public Health, Collage of Medicine and Health Science, Madda Walabu University, Bale Goba, Ethiopia.

Received: 7 March 2019 Accepted: 21 May 2019

Published online: 04 June 2019

\section{References}

1. Mesce D, Clifto D. Abortion facts and figures; population reference bureau Geneva: WHO; 2011.

2. Singh S, Wulf D, Hussain R, Bankole A, Sedgh G. Abortion worldwide: A decade of uneven progress. Guttmacher Institute. Sio, B. (2006). Samoa: a Situation Analysis of Children, Women and Youth, Government of Samoa and UNICEF Pacific; 2009.
3. Rovinsky JJ. Abortion recidivism: a problem in preventive medicine. Obstet Gynecol. 1972:39:649-59.

4. Weitz TA, Kimport K. A need to expand our thinking about "repeat" abortions. Contraception. 2012;85(4):408-12.

5. Rowlands S. More than one abortion. J Fam Plann Reprod Health Care. 2007;33(3):155-8.

6. Jones RK, Singh S, Fine LB, Frohwirth LF. Repeat abortion in the United States. Occasional Report No, 29. http://www.guttmavher.org/pubs/2006/11/ or29.pdf. published November 2006.

7. Heikinheimo O, Gissler M, Suhonen S. Age, parity, history of abortion and contraceptive choices affect the risk of repeat abortion. Contraception. 2008;78(2):149-54

8. St John $\mathrm{H}$, Crithley $\mathrm{H}$, Glasier A. Can we identify women at risk of more than one termination of pregnancy? Contraception. 2005;71(1):31-4.

9. Singh S, Wulf D, Hussain R, Bankole A. Abortion worldwide: a decade of uneven Progress. http://www.guttmacher.org/Pubs/Abortion-Worldwide.pdf. Published 2009.

10. Keenan K, Grundy E, Kenward MG, Leon DA. Women's Risk of Repeat Abortions Is Strongly Associated with Alcohol Consumption: A Longitudinal Analysis of a Russian National Panel Study, 1994-2009. PLoS One. 9(3): e90356. ISSN 1932-6203. https://doi.org/10.1371/journal.pone.0090356.

11. Thapa S, Neupane S. Risk factors for repeat abortion in Nepal. Int J Gynecol Obstet. 2013;120:32-6.

12. Makenzius M. Unintended pregnancy Abortion and Prevention; Women and Men's experiences and Needs. Uppsala: Uppsala University, Department of women's and children's Health, Akademiska Sjukhuset, SE-75185; 2012.

14. Rasch V, Gammeltoft T, Knudsen LB, et al. Induced abortion in Denmark: effect of socio-economic situation and country of birth. Eur J Pub Health. 2008;18:144-9.

13. Helstrom L, Odlind V, Zatterstrom C, et al. Abortion rate and contraceptive practices in immigrant and native women in Sweden. Scand J Public Health. 2003;31:405-10.

15. Niinimaki M, Pouta A, Bloigu A, et al. Frequency and risk factors for repeat abortions after surgical compared with medical termination of pregnancy. Obstet Gynecol. 2009;113:845-52.

16. Fisher WA, Singh SS, Shuper PA, et al. Characteristics of women undergoing repeat induced abortion. CMAJ. 2005:172:637-41.

17. Kilander H, Alehagen S, Svedlund L, Westlund K, Thor J, Brynhildsen J. Likelihood of repeat abortion in a Swedish cohort according to the choice of post-abortion contraception: a longitudinal study. Acta Obstet Gynecol Scand. 2016;95:565-71.

18. Larsson M, Aneblom G, Odlind V, e t a. Reasons for pregnancy termination, contraceptive habits and contraceptive failure among Swedish women requesting an early pregnancy termination. Acta Obstet Gynecol Scand. 2002;81:64-71.

19. Prata N, Holston M, Fraser A, Melkamu Y. Contraceptive use among women seeking repeat abortion in Addis Ababa, Ethiopia. Afr J Reprod Health. 2013; 17(4):56-65.

20. Millar WJ, Wadhera S, Henshaw SK. Repeat abortions in Canada, 1975-1993. Fam Plan Perspect. 1997:29:20-4.

21. Statistics Canada. Therapeutic abortion survey. Canadian Institute for Health Information (custom tabulation). Ottawa: statistics Canada; 2003.

22. Anonymous. Induced abortions and sterilizations in 2004. Helsinki: STAKES (National Research and development Centre for Welfare and Health); 2005.

23. Bascand G. Abortion's year ended December 2005. Wellington: Statistics New Zealand; 2006.

24. Anonymous. Abortions 2005. Stockholm: Socialstyrelsen (National Board of Health and Welfare); 2006.

25. Maina BW, Mutua MM, Sidze EM. Factors associated with repeat induced abortion in Kenya. BMC Public Health. 2015;15:1048. https://doi.org/10.1186/ s12889-015-2400-3.

26. Kinaro J, Ali TEM, Schlangen R, Mack J. Unsafe abortion and abortion care in Khartoum, Sudan. Reprod Health Matters. 2009:17(34):71-7.

\section{Publisher's Note}

Springer Nature remains neutral with regard to jurisdictional claims in published maps and institutional affiliations. 